\title{
Temporal and spatial occurrence of thin phytoplankton layers in relation to physical processes
}

\author{
Margaret M. Dekshenieks ${ }^{1, *}$, Percy L. Donaghay ${ }^{2}$, James M. Sullivan², \\ Jan E. B. Rines ${ }^{2}$, Thomas R. Osborn ${ }^{3}$, Michael S. Twardowski ${ }^{2}$ \\ ${ }^{1}$ Ocean Sciences Department, University of California, Santa Cruz, California 95064, USA \\ ${ }^{2}$ Graduate School of Oceanography, University of Rhode Island, Narragansett, Rhode Island 02882, USA \\ ${ }^{3}$ The Johns Hopkins University, 3400 N Charles Street, Baltimore, Maryland 21218, USA
}

\begin{abstract}
In 1996 three cruises were conducted to simultaneously quantify the fine-scale optical and physical structure of the water column. Data from 120 profiles were used to investigate the temporal occurrence and spatial distribution of thin layers of phytoplankton as they relate to variations in physical processes. Thin layers ranged in thickness from a few centimeters to a few meters. They may extend horizontally for kilometers and persist for days. Thin layers are a recurring feature in the marine environment; they were observed and measured in $54 \%$ of our profiles. Physical processes are important in the temporal and spatial distribution of thin layers. Thin layer depth was closely associated with depth and strength of the pycnocline. Over $71 \%$ of all thin layers were located at the base of, or within, the pycnocline. The strong statistical relationships between thin layers and physical structure indicate that we cannot understand thin layer dynamics without understanding both local circulation patterns and regional physical forcing.
\end{abstract}

KEY WORDS: Thin layer $\cdot$ Phytoplankton $\cdot$ Coastal circulation $\cdot$ East Sound

\section{INTRODUCTION}

Recent advances in optical and acoustical instrumentation, and in deployment techniques, have allowed the detection of persistent, spatially coherent plankton patches that are substantially thinner than the $5 \mathrm{~m}$ scales routinely sampled with bottles and nets (Donaghay et al. 1992). These structures are known as 'thin layers'. Thin layers of phytoplankton and zooplankton range in thickness from $\sim 10 \mathrm{~cm}$ to $\sim 3.5 \mathrm{~m}$. (Donaghay et al. 1992, Cowles \& Desiderio 1993, Cowles et al. 1998, Hanson \& Donaghay 1998). Thin layers have been detected in coastal marine systems ranging from highly protected anoxic basins (Pettaquamscutt Estuary, Rhode Island; Donaghay et al. 1992, Sieburth \& Donaghay 1993, Johnson et al. 1995) to the Oregon Shelf (Cowles \& Desiderio 1993), to open

\footnotetext{
*E-mail: margaret@es.ucsc.edu
}

Baltic waters (Nielson et al. 1990, Bjørnsen \& Nielsen 1991, Carpenter et al. 1995). Thin layers can extend horizontally for several kilometers and persist for several days (Nielson et al. 1990, Bjørnsen \& Nielsen 1991, Rines et al. in press). Such temporally and spatially coherent thin layers can have important impacts not only on the biological structure and dynamics of marine systems (Nielson et al. 1990, Donaghay \& Osborn 1997, Cowles et al. 1998), but also on the optical (Zaneveld \& Pegau 1998) and acoustical (Holliday et al. 1998) properties of those systems.

Although thin layers can occur in many coastal marine systems, we know very little about their frequency and under what physical conditions they will occur. This is due to several factors. First, until recently the sensitivity, stability and dynamic range of sensors has been too limited to make quantitative measurements of thin layers. Second, new deployment techniques have only recently been developed to overcome the inherent technical difficulty of sampling centimeter 
scales from rolling ships. Third, until now much information on thin layers was based on a limited number of profiles, most of which were collected without coincident data on current velocity and often without density data. Lack of coincident data on physical variables has prevented investigators from answering the fundamental question: are physical processes important in the temporal and spatial distribution of thin layers? It has been hypothesized that physical processes and biological-physical interactions play critical roles in thin layer dynamics (Donaghay \& Osborn 1997, Osborn 1998); however, until now there have not been sufficient data to test this hypothesis.

We present results from cruises in East Sound, WA, conducted to quantify the fine-scale optical and physical structure of the water column (Katz et al. 1999, Twardowski et al. 1999). Prior studies of thin layers have been conducted in either highly protected sites, where physical forcing is limited, or in open water sites, where sea conditions make it difficult to simultaneously measure both fine-scale physical and biological processes. East Sound is topographically constrained, which allows it to be sampled synoptically by small boats, yet it is physically dynamic with current velocities of 5 to $40 \mathrm{~cm} \mathrm{~s}^{-1}$ and neap to spring tidal excursions from 0.3 to $3.5 \mathrm{~m}$, respectively. The questions we ask in this study are: (1) How frequently do thin layers occur? (2) Are thin layers ephemeral or recurring? (3) How do the vertical distribution, thickness and intensity of thin layers vary temporally and spatially? (4) Are patterns of thin layer distribution related to patterns of physical structure?

\section{MATERIALS AND METHODS}

Study area. East Sound is a small fjord located near Orcas Island, WA, in the San Juan Archipelago $\left(48^{\circ} 39^{\prime} \mathrm{N}, 122^{\circ} 53^{\prime} \mathrm{W}\right)$. East Sound averages $30 \mathrm{~m}$ in depth, is $12 \mathrm{~km}$ long and $2 \mathrm{~km}$ wide. Orcas Island is bordered by the most active passes exchanging water between the eastern Juan de Fuca Strait and the southern Strait of Georgia (Fig. 1).

Sampling overview. In 1996 three cruises were conducted to simultaneously quantify the fine-scale physical and optical structure of the water column ('May' cruise, 23 May to 1 June; 'June' cruise, 22-26 June: 'August-September' cruise, 28 August to 7 September).

Fine-scale profiles of biological and physical structure were simultaneously measured in 120 profiles (Fig. 2). Sensors were deployed in a high resolution profiling package, capable of simultaneously resolving physical and optical structures on centimeter scales. Temperature, salinity, oxygen and $\mathrm{pH}$ were recorded at depth, using an SBE 911plus CTD (Sea-Bird Electronics, Bellevue, WA). Two WET Labs ac-9s recorded spectral absorption by dissolved substances, Spectral absorption and attenuation by particulate material, and Spectral scattering at 9 wavelengths between 412 and $715 \mathrm{~nm}$ using 2 ac-9s (wet Labs, Philomath, OR). Particulate absorption at $440 \mathrm{~nm}\left(\mathrm{a}_{\mathrm{p}} 440\right)$ was used to quantify finescale optical structure. Particulate absorption at this wavelength is an inherent optical property dominated by phytoplankton chlorophyll a absorption. In contrast to fluorescence, $a_{p} 440$ has the stability and broad dynamic range needed to quantify fine-scale optical structure over the seasonal time scales and wide range of phytoplankton concentrations seen in coastal systems (Twardowski et al. 1999). Current velocity, tidal phase, as well as wind magnitude and direction were simultaneously recorded. Current velocity was measured with an RD Instruments (San Diego, CA) 1200 kHz Acoustic Doppler Current Profiler (ADCP) attached to the side of the vessel, tidal phase was measured with an Endeco tide gauge located halfway up the Sound, and wind was recorded with a Davis weather station on the west bank of the upper Sound. These concurrent measurements are unique. Before 1996, similar centimeter scale biological and physical measurements were usually 


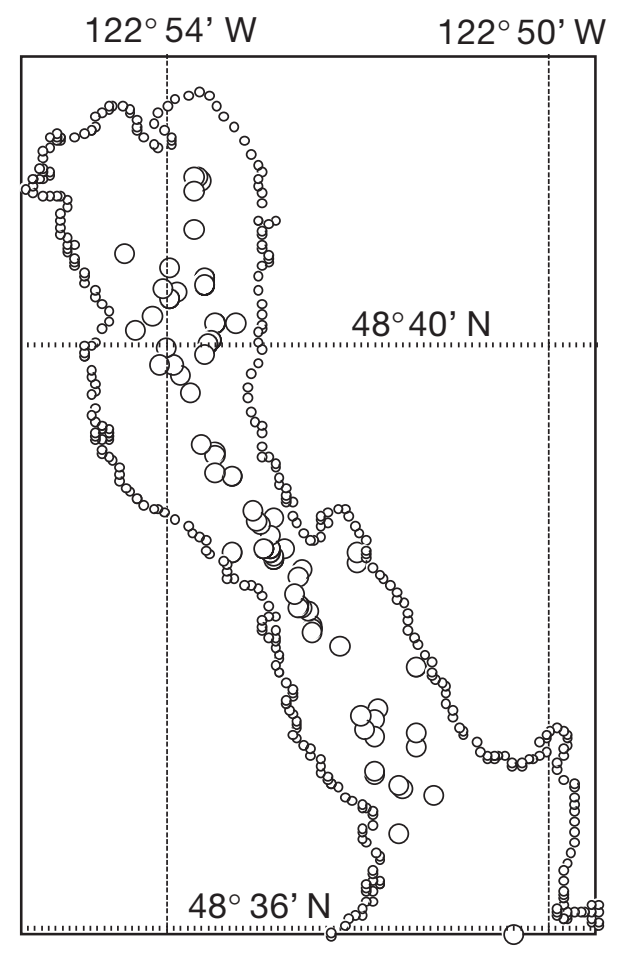

Fig. 2. Spatial distribution of sampling sites in East Sound

made without simultaneous measurements of current and wind fields. Our data set provides a unique opportunity to investigate the temporal and spatial distribution of thin phytoplankton layers relative to physical processes.

Instrument calibration and data analysis. The CTD was calibrated by the manufacturer between cruises. The ac-9s were field-calibrated daily using Nanopure water techniques (Twardowski et al. 1999). Raw ac-9 data were corrected for drift and effects of temperature and salinity (Twardowski et al. 1999). Intakes of all the sensors were at the same depth. This, coupled with direct measurement of flow rates through the sensors, allowed us to precisely calculate the lag time between sampling a layer and individual sensor responses. These time lags are critical to relating the depths of structures measured by independent sensors.

Criteria for identifying thin layers. We defined 4 specific criteria to classify an optical structure as a thin layer and all criteria needed to be met. First, the feature must be present in 2 or more subsequent profiles with the high resolution profiler. This helps eliminate random or isolated accumulations of phytoplankton that lack spatial coherence. Second, the feature must be $\leq 5 \mathrm{~m}$ thick. This thickness was chosen because this is finer than the scale sampled with bottles and nets. Thickness was measured where the optical signal was at half maximum intensity (Fig. 3). Third, the optical signal must contain more than 6 data points. This criterion was chosen because the sampling rate of the ac- 9 is $6 \mathrm{~Hz}$; a single particle or single accumulation of particles moving through the flow cell will therefore produce a signal with 1 to 6 data points. Fourth, the optical signal must be 3 times greater than background levels. This is a conservative criterion that effectively eliminates ephemeral features.

\section{RESULTS AND DISCUSSION}

\section{General thin layer characteristics}

Thin layers were detected in $54 \%$ of 120 profiles (Table 1). We observed up to 3 layers in a single profile. In total, we observed 119 thin layers. Thin layers occurred as shallow as $1.41 \mathrm{~m}$ and as deep as $24.49 \mathrm{~m}$ (mean $6.69 \mathrm{~m}$ ). Most occurred in the upper water column, with roughly $50 \%$ at $<5 \mathrm{~m}$ depth and roughly $80 \%$ at $<10 \mathrm{~m}$ depth (Fig. 4 a). Layers ranged in thick-

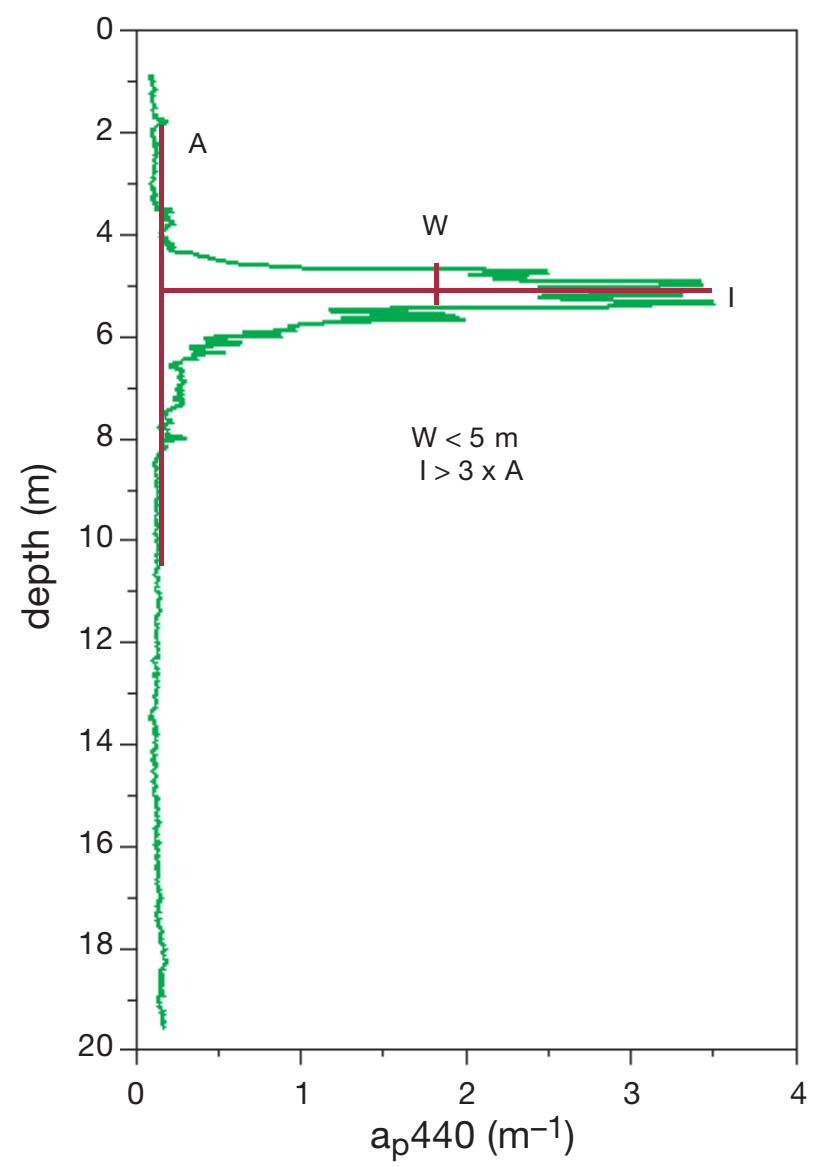

Fig. 3. Criteria used to define a thin layer, where $W, I$ and $A$ represent layer thickness, layer intensity and ambient background intensity, respectively. Particulate absorption, $\mathrm{a}_{\mathrm{p}} 440$ $\left(\mathrm{m}^{-1}\right)$ in green 
Table 1. Thin layer occurrence, encounter, depth, thickness and intensity for all 3 cruises. Minimum and maximum values for thin layer depth, thickness and intensity are indicated in parenthesis before and after average values

\begin{tabular}{|c|c|c|c|c|}
\hline & $\begin{array}{l}\text { All cruises } \\
5 / 23-9 / 7\end{array}$ & $\begin{array}{l}\text { May cruise } \\
5 / 23-6 / 1\end{array}$ & $\begin{array}{c}\text { June cruise } \\
6 / 22-6 / 26\end{array}$ & $\begin{array}{c}\text { Aug-Sep cruise } \\
\text { 8/28-9/7 }\end{array}$ \\
\hline Profiles (\#) & 120 & 53 & 29 & 38 \\
\hline Profiles with layers (\#) & 65 & 36 & 7 & 22 \\
\hline Percentage with layers (\%) & 54 & 68 & 24 & 58 \\
\hline Total layers encountered (\#) & 119 & 75 & 12 & 32 \\
\hline Depth (m) & $(1.41) 6.69(24.49)$ & $(1.84) 7.10(21.25)$ & $(4.41) \quad 6.82(8.52)$ & (1.41) 5.69 (24.29) \\
\hline Thickness (m) & $(0.12) \quad 1.20 \quad(3.61)$ & $(0.12) \quad 0.94 \quad(3.42)$ & $(0.31) 1.25$ (2.41) & $(0.61) \quad 1.79 \quad(3.61)$ \\
\hline Intensity $\left(\mathrm{m}^{-1}\right)$ & $\begin{array}{lll}(0.25) & 1.33 & (6.45)\end{array}$ & $\begin{array}{lll}(0.32) & 1.65 & (6.45)\end{array}$ & (0.43) $0.93(1.40)$ & $\left(\begin{array}{lll}0.25) & 0.72 \quad(1.34)\end{array}\right.$ \\
\hline
\end{tabular}
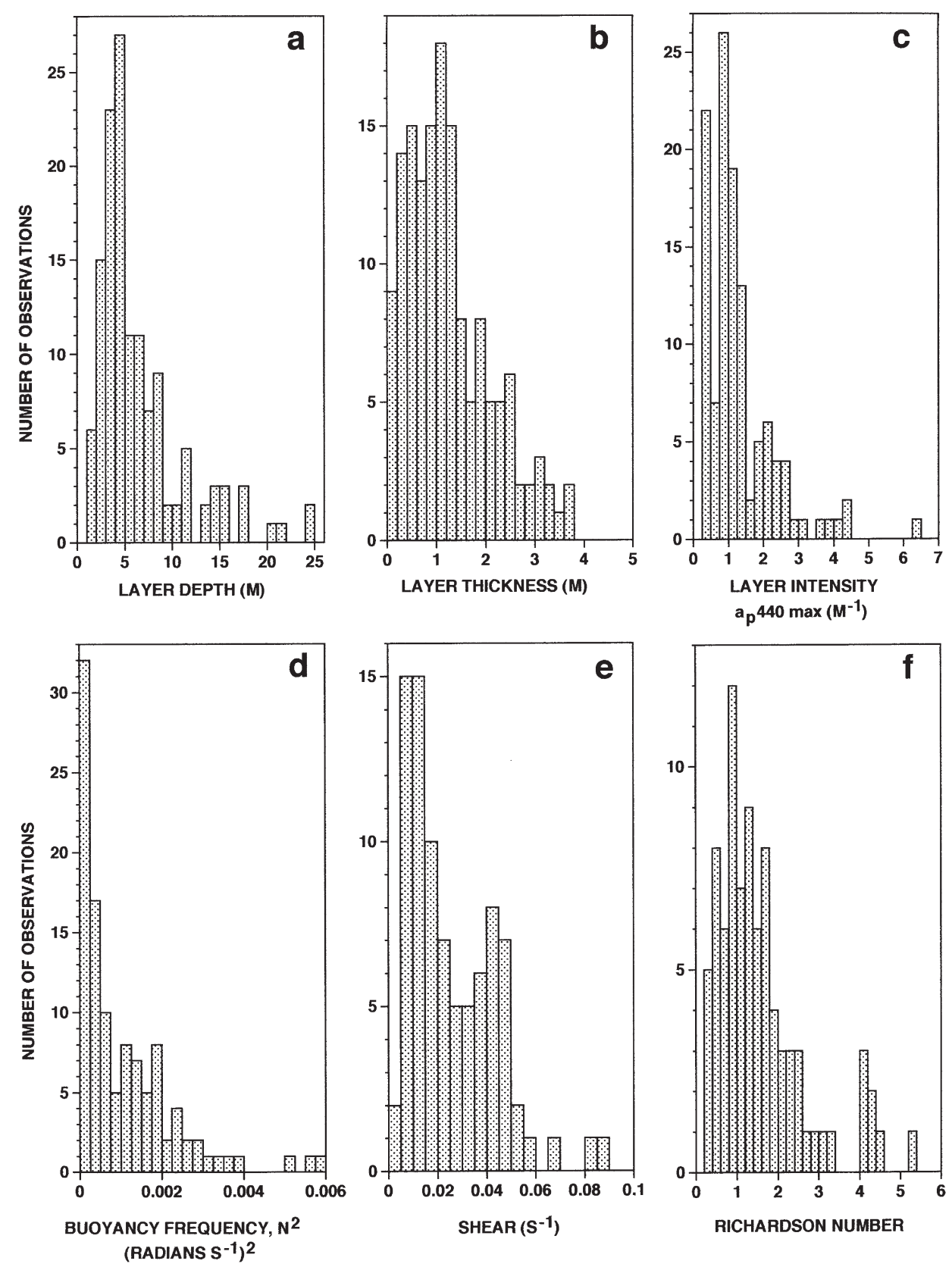

Fig. 4. Histograms: (a) layer depth, m; (b) layer thickness, $\mathrm{m}_{\mathrm{i}}$ (c) layer intensity, $\mathrm{a}_{\mathrm{p}} 440$, $\mathrm{m}^{-1}$; (d) buoyancy frequency, (rads/s) ${ }^{2}$; (e) shear, $\mathrm{s}^{-1}$; (f) Richardson number. Buoyancy frequency, shear and Richardson number calculated from measurements at exact location of each thin layer 
ness from $0.12 \mathrm{~m}$ to $3.61 \mathrm{~m}$ (mean $1.20 \mathrm{~m}$ ). Roughly $44 \%$ of layers were $<1 \mathrm{~m}$ in thickness, and $80 \%$ of layers were $<2 \mathrm{~m}$ in thickness (Fig. $4 \mathrm{~b}$ ). This indicates a clear separation in scale between thin layers, and the more traditional deep chlorophyll a maximum (Anderson 1969). Layer intensity, or $\mathrm{a}_{\mathrm{p}} 440$, ranged from 0.25 to $6.45 \mathrm{~m}^{-1}$ (mean $1.33 \mathrm{~m}^{-1}$ ) (Table 1, Fig. 4c). About $72 \%$ of the thin layers had absorption intensities that ranged from 0.25 to $1.5 \mathrm{~m}^{-1}$ (Fig. 4c).

There is a second class of thin optical layer adjacent to the bottom. These bottom layers were found in 31 $(26 \%)$ of the profiles. They ranged from 0.23 to $3.11 \mathrm{~m}$ in thickness (mean $1.30 \mathrm{~m}$ ). Bottom layer intensities ranged from 0.26 to $2.24 \mathrm{~m}^{-1}$ (mean $0.80 \mathrm{~m}^{-1}$ ). Thus, bottom layers had similar thickness to and slightly lower intensities than water column thin layers. We do not include bottom layers in these analyses (see Rines et al. in press).

Buoyancy frequency, shear, and Richardson number were calculated from physical measurements made at the exact depth interval of each thin layer. Layers occurred over a broad range of buoyancy frequencies (Fig. 4d). Buoyancy frequency indicates the strength of the vertical density gradient. Roughly $40 \%$ of all layers occurred at relatively low buoyancy frequency $\left[<0.0005(\mathrm{rads} / \mathrm{s})^{2}\right]$, while $60 \%$ were in regions with buoyancy frequencies $>0.0005(\mathrm{rads} / \mathrm{s})^{2}$. Layers in regions of higher buoyancy frequency were most often associated with the pycnocline. Layers occurred over a broad range of shear (Fig. 4e). There were 2 modes in the shear histogram, the first at relatively low shear [0 to $0.025 \mathrm{~s}^{-1}$ ] and the second at moderate shear $\left[0.025\right.$ to $0.05 \mathrm{~s}^{-1}$ ]. Only $5 \%$ of all thin layers occurred at shear $>0.05 \mathrm{~s}^{-1}$. No layers were found in regions where the Richardson number was $<0.23$ (Fig. 4f). In general, when the Richardson number is $<0.25$ the water column is unstable (Mann \& Lazier 1991), and would not support thin layer development.

Relationships of thin layer depth, thickness and intensity to wind speed were also investigated. Wind speeds (Fig. 5) are $1 \mathrm{~h}$ averages prior to the start of each profile. Neither thin layer depth nor thickness showed any clear relationship to wind speed, but layer intensity did. Highest layer intensities $\left(>2.3 \mathrm{~m}^{-1}\right)$ occurred at lower wind speeds $\left(<4 \mathrm{~m} \mathrm{~s}^{-1}\right)$. In East Sound, surface waters from 2 to $10 \mathrm{~m}$ are strongly influenced by wind forcing. When wind speeds are low, advection of and mixing in the surface layer are low. Thus, in situ growth rates for phytoplankton might maintain high biomass and might subsequently maintain higher layer intensities.

\section{Thin phytoplankton layers and the pycnocline}

Thin layer depth was closely associated with depth and strength of the pycnocline. Roughly $62 \%$ of all thin layers were at the base of the pycnocline (Fig. 6a). This pattern was observed on all cruises, but was strongest in May. Approximately $9 \%$ of thin layers were distributed
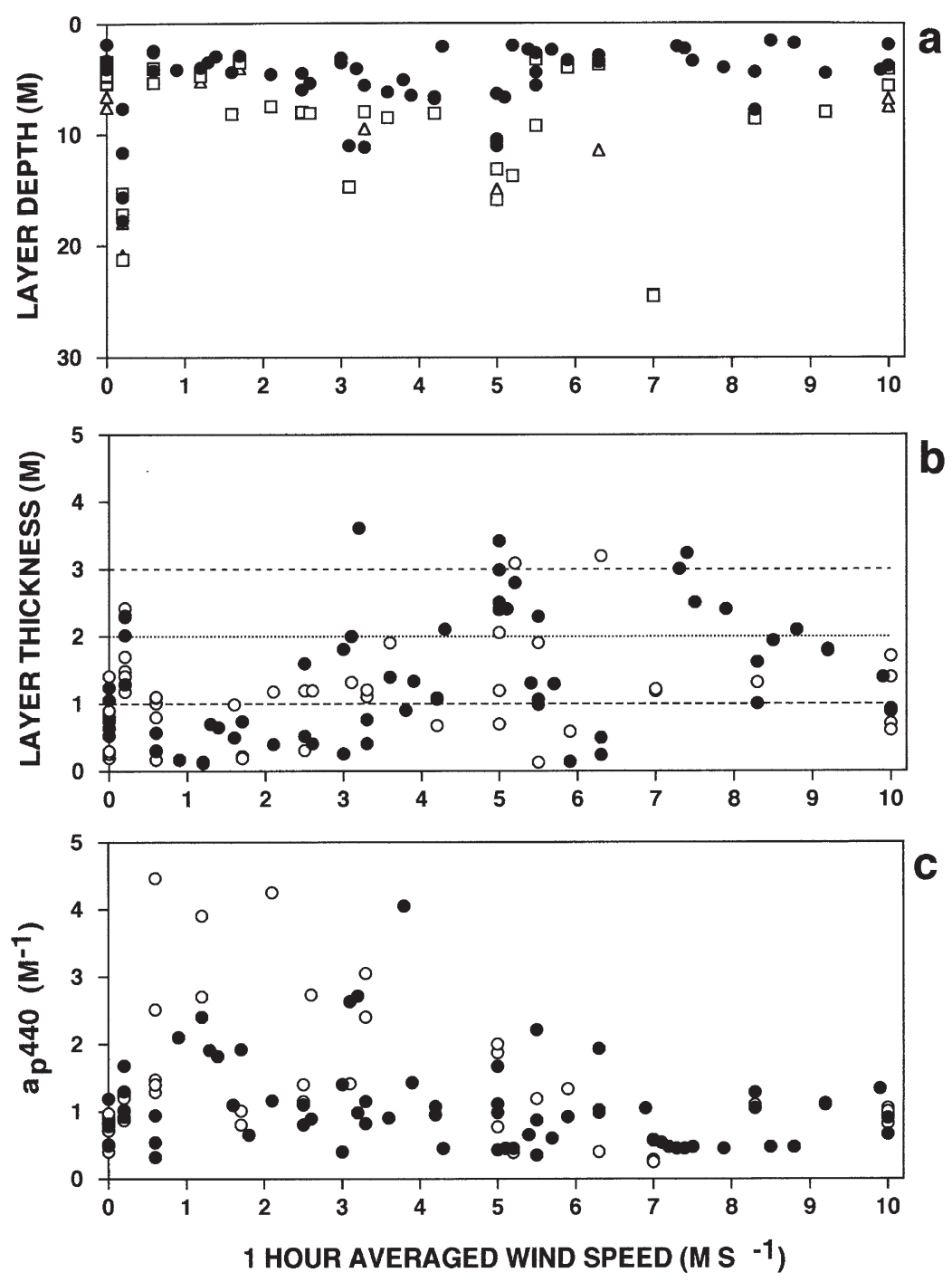

Fig. 5. Layer attributes: (a) layer depth, m; (b) layer thickness, m; (c) layer intensity, $\mathrm{a}_{\mathrm{p}} 440, \mathrm{~m}^{-1}$ versus wind speed, $\mathrm{m} \mathrm{s}^{-1}$. Wind speeds are $1 \mathrm{~h}$ averages prior to start of each profile 


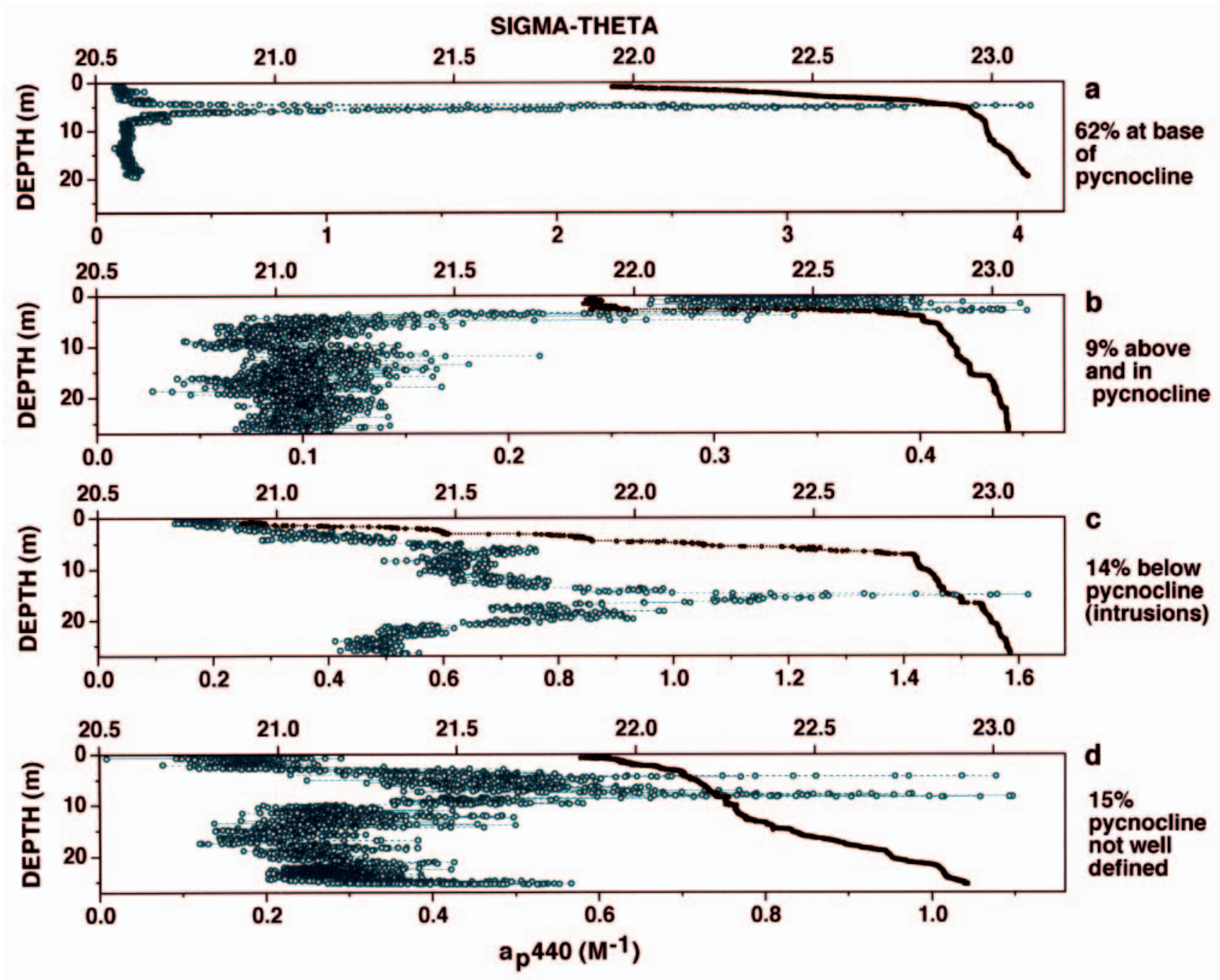

Fig. 6. Statistics showing relationship between thin layers and pycnocline: (a) layer is located at base of pycnocline; (b) layer is spread above and in pycnocline; (c) layer is below pycnocline; (d) thin layers exist but pycnocline is not well defined

from the surface to just within the pycnocline (Fig. 6b). This pattern was observed in August-September, when surface water with high biomass was being advected into the Sound by persistent southerly winds. In total, $71 \%$ of thin layers were directly associated with the pycnocline. Of the remaining $29 \%$, half were below the pycnocline (Fig. 6c) and often associated with advected water masses. The rest were sampled at times when density increased slowly and uniformly with depth and there was no well-defined pycnocline (Fig. 6d).

Temporal occurrence of thin phytoplankton layers and physical conditions

To understand the occurrence of thin phytoplankton layers over time, it is necessary to understand both the local circulation patterns and the regional physical forcing which influences water mass movement into East Sound. Wind and tidal forcing are the primary influences on circulation patterns in the Sound. The surface layer ( 2 to $10 \mathrm{~m}$ ) flows with the wind; deeper flows are tidal. Most thin layers were at the density interface between the wind forced surface layer and the tidally influenced layer below (cf. Fig. 4a).

East Sound's water masses also change over time. These water masses result from mixing cooler, higher salinity water from the Strait of Juan de Fuca with warmer, lower salinity water from the Strait of Georgia (Redfield 1950) (cf. Fig. 1). The Strait of Georgia is heavily influenced by the Fraser River, which supplies over $80 \%$ of the total annual freshwater to the Straits (Thomson 1981). The river's maximum outflow occurs from late May to early June. Between 25 and 27 May 1996, a sustained north wind combined with a neap tide produced the proper conditions for a plume of low 
salinity water from the Strait of Georgia to be advected into East Sound. This low salinity plume moved rapidly into the system and displaced the pycnocline to a depth of $17 \mathrm{~m}$. The deepest thin layers were found on 27 May after this low salinity event, and this was the only time we observed a plume of low salinity water in 1996. The depth of thin layers is obviously highly dependent upon both local circulation patterns and episodic low salinity events driven by regional wind and tidal forcing.

To discern temporal trends in layer attributes, we plot both layer thickness and intensity temporally (Fig. 7a,b). Layer thickness is related to strength of the pycnocline, which is primarily a function of the physi- cal characteristics of the water masses advected into the Sound plus thermal heating. The thinnest layers $(<0.31 \mathrm{~m})$ were encountered during May. In June, layer thickness ranged from 0.31 to $2.41 \mathrm{~m}$, and no layers $<0.31 \mathrm{~m}$ were encountered. During AugustSeptember, layer thickness ranged from 0.61 to $3.61 \mathrm{~m}$, and no layers $<0.61 \mathrm{~m}$ were sampled. During May, the density profile in East Sound was heavily influenced by lower salinity water being advected southward from the Fraser River, and the mean density increase across the pycnocline was the greatest (0.31 sigmatheta). In addition to the influence of the Fraser River, spring tides occurred during the last few days of May. The combination of strong density gradients and
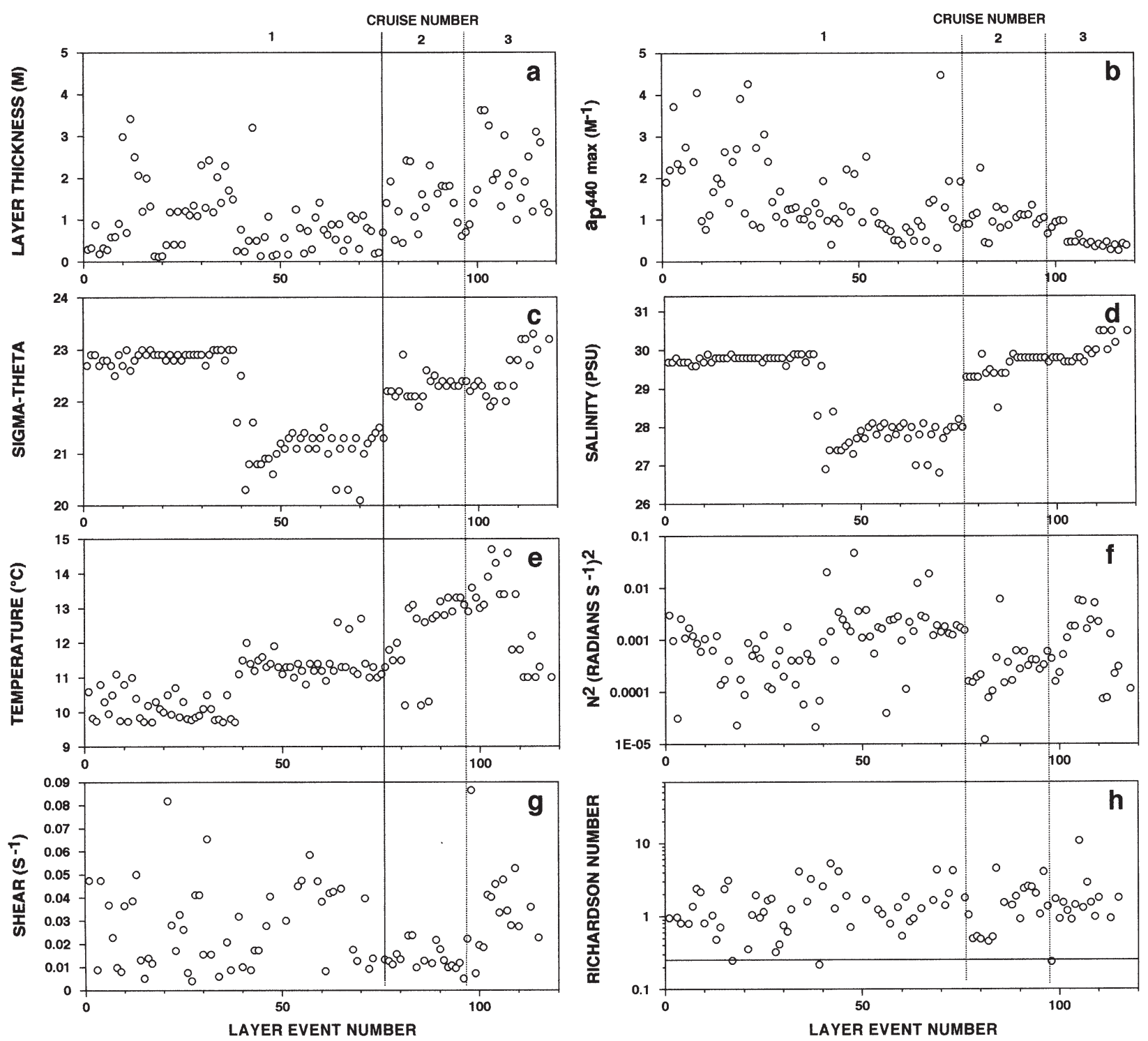

Fig. 7. Thin layer attributes and associated physical attributes plotted sequentially in the order in which they were encountered: (a) layer thickness, $\mathrm{m}_{i}$ (b) layer intensity, $\mathrm{a}_{\mathrm{p}} 440, \mathrm{~m}^{-1}$; (c) sigma-theta; (d) salinity, psu; (e) temperature, ${ }^{\circ} \mathrm{C}_{i}$ (f) buoyancy frequency, $(\mathrm{rads} / \mathrm{s})^{2} ;(\mathrm{g})$ shear, $\mathrm{s}^{-1}$; (h) Richardson number; the solid horizontal line in (h) corresponds to Ri $=0.25$ 
higher shears produced by spring tides supported the thinnest layers $(0.12$ to $0.31 \mathrm{~m})$. Most AugustSeptember layers occurred from the surface to just within the shallow, late-summer pycnocline. These thin layers were more accurately classified as 'surface expressions' and differed from their May counterparts. During August-September, the mean density increase across the pycnocline was only 0.16 sigma-theta, and the pycnocline was consistently at 1 to $5 \mathrm{~m}$. The August-September density profiles were primarily the result of heating.

There was a clear seasonal trend in layer intensity. The mean intensity decreased from May to AugustSeptember. Layers with the most intense signal $\left(1.65 \mathrm{~m}^{-1}\right)$ were encountered in May, while layers with the least intense signal $\left(0.72 \mathrm{~m}^{-1}\right)$ were encountered in August-September (Table 1, Fig. 7b). Variations in phytoplankton production and seasonal succession may be important to the intensity. Cushing (1959) identified generalized patterns of fluctuation in the seasonal amplitude of algal and herbivore production for arctic, temperate and tropical regions. Dexter's (1983) work in East Sound closely matches Cushing's conceptual model, suggesting that East Sound is likely to be typical of many temperate, neritic ecosystems. Our May cruise took place during the spring phytoplankton bloom, and we measured the highest intensity signal during the bloom. Our June and AugustSeptember cruises fell within the summer, high herbivore-low phytoplankton period and the measured intensity signal was considerably lower.

To discern temporal trends in physical attributes associated with layers, we plot sigma-theta, salinity, temperature, buoyancy frequency, shear and Richardson number as time series (Fig. $7 \mathrm{c}-\mathrm{h}$ ). In early May (layers 1 to 40), most layers were associated with a specific sigma-theta and salinity and a narrow range of temperature (Fig. $7 \mathrm{c}-\mathrm{e}$ ). These layers were part of a bloom of the diatom Pseudo-nitzschia that persisted as a coherent thin layer for $9 \mathrm{~d}$ in close association with waters with a salinity of $29.78 \mathrm{psu}$ (Rines et al. in press). Toward the end of May (layers 41 to 75), layers developed in waters that were distinctly lower in sigma-theta (e.g. the result of the 27 May plume of lower salinity, warmer water). This second group persisted until the end of May. During June (layers 76 to 87), thin layers occurred over a narrow range of sigma-theta and salinity, while temperature varied by up to $3^{\circ} \mathrm{C}$. During August-September, layers were initially associated with a relatively narrow range of sigma-theta and salinity. Later, sigma-theta and salinity increased while temperature decreased.

There were no clear temporal trends in buoyancy frequency, shear and Richardson number associated
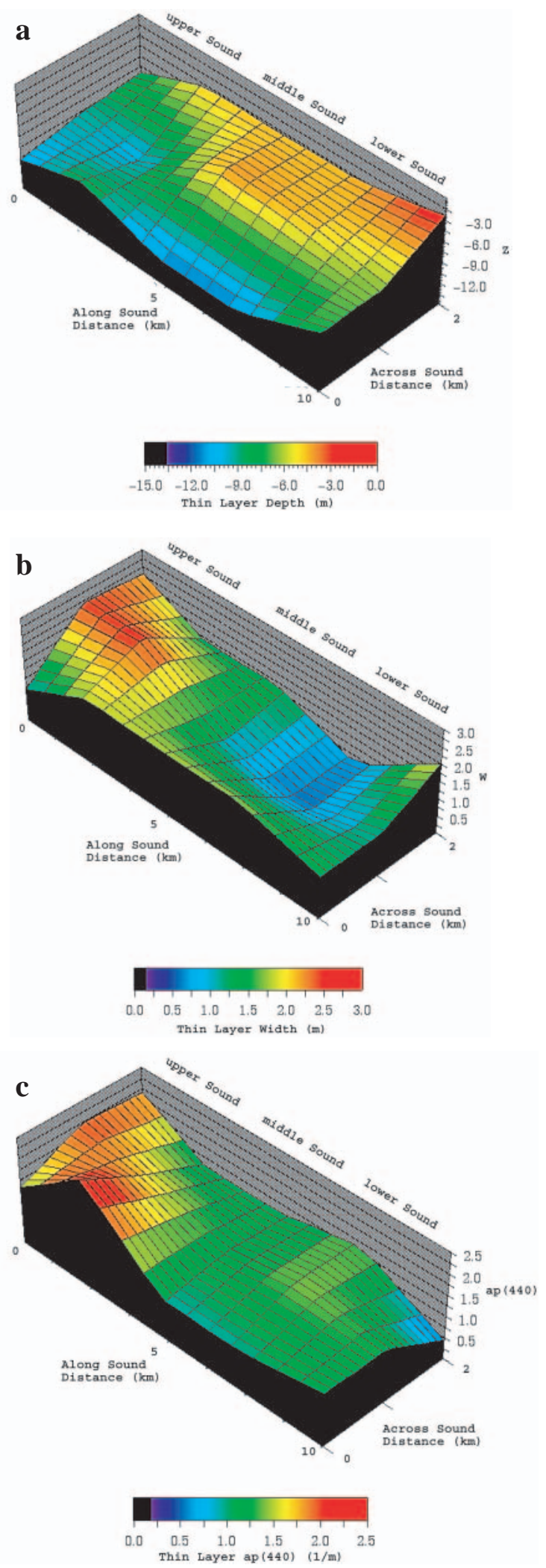

Fig. 8. East Sound: (a) composite surface plot of thin layer depth distribution, $\mathrm{m}_{i}(\mathrm{~b})$ composite surface plot of thin layer thickness distribution, $m_{i}$ (c) composite surface plot of thin layer particulate absorption distribution, $\mathrm{a}_{\mathrm{p}} 440, \mathrm{~nm}$ 
with layers (Fig. 7f,g,h). Buoyancy frequency varied over 3 orders of magnitude. This variability is consistent with the fact that thin layers were not always associated with the steepest region of the pycnocline. Shear was also highly variable $\left(0.003\right.$ to $\left.0.088 \mathrm{~s}^{-1}\right)$. However, almost all Richardson numbers were above 0.25 . This is consistent with the hypothesis that thin layers can only persist in regions where buoyancy is sufficient to suppress turbulent flow.

\section{Spatial patterns of thin phytoplankton layers and physical conditions}

Thin layer depths were spatially variable across the Sound (Fig. 8a). Generally, thin layers were shallower (2 to $5 \mathrm{~m}$ ) on the eastern side, and deeper (6 to $10 \mathrm{~m}$ ) on the western side. This trend is most pronounced in the lower and middle regions of the Sound, and closely follows both the slope in the 'layer of no motion' evident in current profiles, and the across-Sound slope in the pycnocline (Fig. 9). The patterns of circulation differ acrossSound. In general, the tide floods more strongly on the eastern side and ebbs more strongly on the western side. A combination of bathymetry at the mouth and Coriolis force produce this pattern.

Thin layer depths varied spatially from south to north (Fig. 8a). In the lower and middle Sound, thin layers were generally shallower than in the upper Sound, following the pycnocline which slopes downward from south to north (Fig. 9). This slope results from the near continuous advection of lower density surface water up the Sound due to predominantly southerly winds. Clearly, circulation patterns influence spatial patterns in thin layer depth.
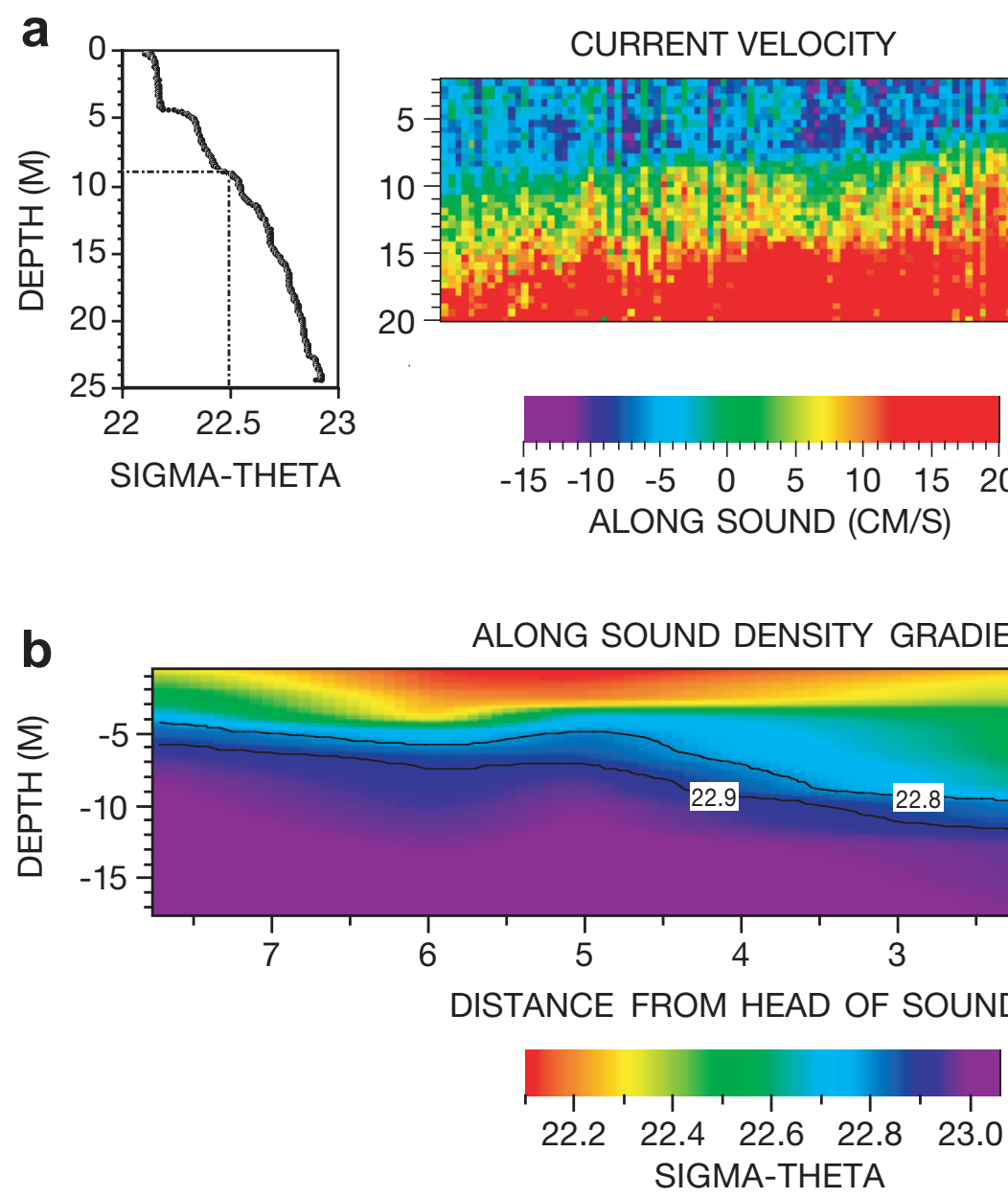

Fig. 9. (a) Colored panel represents current velocities in transect across middle portion of East Sound. View to the north, looking up-Sound from mouth; left-hand side west, right-hand side east. Positive velocities in up-Sound (northward) direction, negative velocities are in down-Sound (southward) direction. Line graphs to left and right represent sigma-theta profiles from western and eastern sides of the transect respectively. Depth location of 22.5 sigma-theta denoted on each profile. (b) Contours of density measured with 8 CTD profiles taken along East Sound. View to the west, looking across-Sound from eastern shore; mouth of 
The strength of the pycnocline can be related to spatial patterns in layer thickness. The increase in density across the pycnocline is consistently greater (mean 0.20 sigma-theta) on the eastern side of the lower and middle Sound. The thinnest layers $(0.25$ to $1.0 \mathrm{~m}$ ) were also located in these regions. In the upper Sound, the density increase across the pycnocline is consistently lower (mean 0.05 sigma-theta) and was associated with thickest layers (2.0 to $3.5 \mathrm{~m}$ ) (Fig. 8b).

Circulation patterns also contribute to observed patterns in intensity. Layer intensity was highest (1.5 to $2.5 \mathrm{~m}^{-1}$ ) in the north (Fig. 8c). Predominant southerly winds produce a 'jet' of northward moving water in the central region of the upper Sound. Surface water is advected up the center of the Sound, and surface water then moves down-Sound along the peripheries indicating recirculating surface waters. This recirculation retains phytoplankton in the upper Sound; hence, this is the first location where spring blooms occur (Dexter 1983).

\section{CONCLUSIONS}

Finding thin layers in $54 \%$ of the 120 profiles taken over 4 mo indicates that thin layers can be a recurrent feature of coastal systems. Furthermore, the fact that these layers ranged in thickness from 0.12 to $3.61 \mathrm{~m}$, with $80 \%$ of all thin layers measuring $<2 \mathrm{~m}$ in thickness, indicates that conventional sampling methods would underestimate both the intensity and abundance of thin layers. Thus, we conclude that thin layers are certainly a real feature, they are common, and they clearly indicate another scale of biological variability.

Physical structures and processes play a critical role in controlling the temporal and spatial distribution of thin layers. Over $71 \%$ of all thin layers were associated with the pycnocline. Because the pycnocline in East Sound varies temporally and spatially, thin layer distribution is also variable in both time and space. The strong statistical relationships between thin layers and physical structure indicates that we cannot understand the vertical position or lateral distribution of thin layers without understanding both local circulation patterns and regional physical forcing. Physical processes also play a critical role in thin layer dynamics. Thus, simultaneous measurement of fine-scale optical structure along with physical structure and physical processes can help in the prediction of thin layer occurrence.

Thin layers in East Sound occur over a broad range of buoyancy frequency and shear, and we expect such layers to occur under similar physical conditions in other coastal systems, providing that biological conditions are also favorable. This is consistent with theoretical models (Donaghay \& Osborn 1997) and with observations of thin layers in coastal systems (Ryther 1955, Nielson et al. 1990, Bjørnsen \& Nielsen 1991, Carpenter et al. 1995). Our results also indicate that there are physical conditions under which thin layers do not occur, e.g. where the water column is turbulent (Ri <0.23). Thus, we do not expect persistent thin layers in tidally mixed regions, nor do we expect thin layers in wind mixed surface layers. These results clearly connect physical structure, physical processes and the presence of thin layers in East Sound. With this new understanding we can identify other coastal regions that have a high probability of supporting thin layer development.

Acknowledgements. We thank D. Van Holliday and Casey Moore for help with this research. We thank Eric Shulenberger and 2 anonymous reviewers for their constructive comments and Lauren Wilkinson for help with this manuscript. This research was supported by the Office of Naval Research Physical Oceanography Program, grant N00014-981-0388 to M.M.D., P.L.D. and T.R.O., and the Office of Naval Research Biological/Chemical Oceanography Program, grants N00014-95-1-0211 and N00014-95-1-0225 to P.L.D.

\section{LITERATURE CITED}

Anderson GC (1969) Subsurface chlorophyll maximum in the Northeast Pacific Ocean. Limnol Oceanogr 14:368-391

Bjornsen PK, Nielsen TG (1991) Decimeter scale heterogeneity in plankton during a pycnocline bloom of Gyrodinium aureolum. Mar Ecol Prog Ser 73:263-267

Carpenter EJ, Janson S, Boje R, Pollehne F, Chang J (1995) The dinoflagellate Dinophysis norvegica: biological and ecological observations in the Baltic Sea. Eur J Phycol 30:1-9

Cowles TJ, Desiderio RA (1993) Resolution of biological micro-structure through in situ fluorescence emission spectra. Oceanography 6(3):105-111

Cowles TJ, Desiderio RA, Carr ME (1998) Small-scale planktonic structure: persistence and trophic consequences. Oceanography 11(1):4-9

Cushing DH (1959) The seasonal variation in oceanic production as a problem in population dynamics. J Cons Int Explor Mer 24:455-464

Dexter BL (1983) Developmental grazing capabilities of Pseudocalanus sp. and Acartia clausi (CI to Adult). PhD thesis, Oregon State University, Corvallis, OR

Donaghay PL, Osborn TR (1997) Toward a theory of biological-physical control of harmful algal bloom dynamics and impacts. Limnol Oceanogr 42(5):1283-1296

Donaghay PL, Rines HM, Sieburth JM (1992) Simultaneous sampling of fine scale biological, chemical and physical structure in stratified waters. Arch Hydrobiol 36:97-108

Hanson AK, Donaghay PL (1998) Micro- to fine-scale chemical gradients and layers in stratified coastal waters. Oceanography 11(1):10-17

Holliday DV, Pieper RE, Greenlaw CF, Dawson JK (1998) Acoustical sensing of small scale vertical structures in zooplankton assemblaqes. Oceanography II (1):18-23

Johnson PW, Donaghay PL, Small EB, Sieburth JMcN (1995) Ultrastructure and ecology of Perispira ovum (Ciliophora: Litostomatea): an aerobic, planktonic ciliate that sequesters 
the chloroplasts, mitochondria, and paramylon of Euglena proxima in a micro-oxic habitat. J Eukaryot Microbiol 42(3):323-335

Katz J, Donaghay PL, Zhang J, King S, Russell K (1999) Submersible holocamera for detection of particle characteristics and motions in the ocean. Deep-Sea Res I 46: 1455-1481

Mann KH, Lazier JRN (1991) Dynamics of marine ecosystems. Blackwell Scientific Publications, Oxford

Nielsen TG, Kiørboe T, Bjørnsen PK (1990) Effect of a Chrysochromulina polylepis subsurface bloom on the planktonic community. Mar Ecol Prog Ser 62:21-35

Osborn TR (1998) Finestructure, microstructure, and thin layers. Oceanography 11(1):36-43

Redfield AC (1950) Note on the circulation of a deep estuary: the Juan de Fuca-Georgia Straits. In: Proceedings of the colloquium on flushing of estuaries. Woods Hole Oceanographic Institution, Woods Hole, MA, p 175-177

Rines JEB, Donaghay PL, Dekshenieks MM, Sullivan JM, Twardowski MS (in press) Thin layers and camouflage:

Editorial responsibility: Barry and Evelyn Sherr (Contributing Editors), Corvallis, Oregon, USA hidden Pseduo-nitzschia populations in a fjord in the San Juan Islands, Washington, USA. Mar Ecol Prog Ser

Ryther JH (1955) Ecology of autotrophic marine dinoflagellates with reference to red water conditions. In: Johnson $\mathrm{FH}$ (ed) The luminescence of biological systems. American Association for the Advancement of Science, Washington, DC, p 387-413

Sieburth JM, Donaghay PL (1993) Planktonic methane production and oxidation within the algal maximum of the pycnocline: seasonal fine-scale observations in an anoxic estuarine basin. Mar Ecol Prog Ser 100:3-15

Thomson RE (1981) Oceanography of the British Columbia coast. Can Spec Publ Fish Aquat Sci 56

Twardowski MS, Sullivan JM, Donaghay PL, Zaneveld JRV (1999) Microscale quantification of the absorption by dissolved and particulate material in coastal waters with an ac-9. J Atmos Ocean Tech 16:691-707

Zaneveld JR, Pegau WS (1998) A model for the reflectance of thin layers, fronts, and internal waves and its inversion. Oceanography 11(1):44-47

Submitted: July 17, 2000; Accepted: January 31, 2001 Proofs received from author(s): November 20, 2001 